\title{
Preadipocyte Factor-1 Concentrations in Patients With Anorexia Nervosa: the Influence of Partial Realimentation
}

\author{
P. KAVÁLKOVÁ ${ }^{1}$, I. DOSTÁlOVÁ ${ }^{1}$, D. HALUZÍKOVÁ ${ }^{1,2}$, P. TRACHTA $^{1}$, \\ V. HANUŠOVÁ ${ }^{1}$, Z. LACINOVÁ ${ }^{1}$, H. PAPEŽOVÁ ${ }^{3}$, D. DOMLUVILOVÁ ${ }^{3}$, V. ZIKÁN ${ }^{1}$, \\ M. HALUZÍK ${ }^{1}$ \\ ${ }^{1}$ Third Department of Medicine, First Faculty of Medicine, Charles University and General \\ University Hospital, Prague, Czech Republic, ${ }^{2}$ Department of Sports Medicine, First Faculty of \\ Medicine, Charles University and General University Hospital, Prague, Czech Republic, \\ ${ }^{3}$ Department of Psychiatry, First Faculty of Medicine, Charles University and General University \\ Hospital, Prague, Czech Republic
}

Received February 18, 2011

Accepted November 14, 2011

On-line January 31, 2012

\section{Summary}

Preadipocyte factor-1 (Pref-1) is a member of epidermal growthfactor like family of proteins that regulates adipocyte and osteoblast differentiation. Experimental studies suggest that circulating Pref-1 levels may be also involved in the regulation of lipid and glucose metabolism and energy homeostasis. We hypothesized that alterations in Pref- 1 levels may contribute to the ethiopathogenesis of anorexia nervosa or its underlying metabolic abnormalities. We measured Pref- 1 concentrations and other hormonal, biochemical and anthropometric parameters in eighteen patients with anorexia nervosa and sixteen healthy women and studied the influence of partial realimentation of anorexia nervosa patients on these parameters. The mean duration of realimentation period was $46 \pm 2$ days. At baseline, anorexia nervosa patients had significantly decreased body mass index, body weight, body fat content, fasting glucose, serum insulin, TSH, free T4, leptin and total protein. Partial realimentation improved these parameters. Baseline serum Pref- 1 levels did not significantly differ between anorexia nervosa and control group $(0.26 \pm 0.02$ vs. $0.32 \pm 0.05 \mathrm{ng} / \mathrm{ml}, \mathrm{p}=0.295)$ but partial realimentation significantly increased circulating Pref-1 levels $(0.35 \pm 0.04$ vs. $0.26 \pm 0.02 \mathrm{ng} / \mathrm{ml}, \mathrm{p}<0.05)$. Postrealimentation Pref- 1 levels significantly positively correlated with the change of body mass index after realimentation $(r=0.49$, $p<0.05)$. We conclude that alterations in Pref- 1 are not involved in the ethiopathogenesis of anorexia nervosa but its changes after partial realimentation could be involved in the regulation of adipose tissue expansion after realimentation.

\section{Key words}

Preadipocyte factor-1 - Anorexia nervosa - Realimentation • Adipose tissue

\section{Corresponding author}

M. Haluzik, Third Department of Medicine, First Faculty of Medicine, U Nemocnice 1, 12800 Prague 2, Czech Republic. E-mail: mhalu@lf1.cuni.cz

\section{Introduction}

Anorexia nervosa (AN) is a psychiatric disorder characterized by malnutrition due to chronically decreased food intake caused by distorted body image and inappropriate fear of obesity (Hoek and van Hoeken 2003, Sigman 2003). Detailed ethiopathogenesis of AN is still not completely known (Foppiani et al. 1998). Numerous alterations in circulating levels of appetiteregulating hormones, including leptin, ghrelin and others together with various other hormonal and metabolic abnormalities have been previously documented in these patients (Baranowska et al. 1997, Stoving et al. 1999, Tanaka et al. 2003, Dostalova et al. 2009, Dostalova and Haluzik 2009). However, most if not all of these changes appear rather secondary to compensate for chronically decreased food intake and malnutrition.

One of the typical features of patients with anorexia nervosa is severely decreased body fat content 
(Frisch and McArthur 1974). Consequently, endocrine function of adipose tissue is markedly altered with significantly decreased serum leptin concentrations and increased serum adiponectin levels (Grinspoon et al. 1996, Tagami et al. 2004, Housova et al. 2005, Dolezalova et al. 2007, Haluzikova et al. 2009).

Preadipocyte factor-1 (Pref-1) is a member of epidermal growth-factor like family of proteins that plays an important role in the regulation of adipocyte and osteoblast differentiation (Smas and Sul 1993, Wang et al. 2006). Recent studies in mesenchymal stem cells have demonstrated a possible inverse relationship between osteoblast and adipocyte differentiation since both osteoblasts and adypocytes has common progenitor (Beresford et al. 1992, Verma et al. 2002) suggesting that Pref-1 might be also indirectly involved in the regulation of bone metabolism and bone mineral density.

Within adipose tissue, Pref- 1 is specifically expressed by preadipocytes but not by adipocytes and therefore it can be used as a preadipocyte marker (Lee et al. 2003). Other tissues such as the liver can also produce Pref-1 (Wang et al. 2006). Pref-1 is released into the circulation suggesting that it may have also systemic role in other organs and tissues. Experimental studies have shown that overexpression of Pref-1 in mice lead to lower adipose tissue mass, hypertriglyceridemia, decreased glucose tolerance and lower insulin sensitivity implying a possible role for this factor in the regulation of energy homeostasis and glucose metabolism (Villena et al. 2008).

Very little is known about regulation of circulating Pref-1 levels in patients with anorexia nervosa and the influence of partial realimentation on its levels. Based on the experimental data showing decreased adipose tissue mass and other energy homeostasis alterations in Pref-1 overexpressing mice we hypothesized that alterations in Pref-1 levels may contribute to the ethiopathogenesis of anorexia nervosa or to regulation of response to partial realimentation. To this end, we measured Pref-1 and other hormonal, biochemical and anthropometric parameters in patients with anorexia nervosa and healthy normal-weight women and studied the influence of partial realimentation on these parameters.

\section{Methods}

\section{Study subjects}

Eighteen previously untreated female patients with AN (age: $24.39 \pm 1.21$ years; body mass index (BMI):
$15.58 \pm 0.28 \mathrm{~kg} / \mathrm{m}^{2}$; body fat content $10.31 \pm 1.8 \%$ ) and sixteen age- and sex-matched healthy controls (age: $22.69 \pm 0.76$ years; BMI: $21.8 \pm 0.51 \mathrm{~kg} / \mathrm{m}^{2}$; body fat content $20.07 \pm 1.4 \%$ ) were included in the study. The diagnosis of eating disorder was based on Diagnostic Statistical Manual IV diagnostic system (DSM-IV). Patients were referred by local psychiatrist and they were hospitalized in the Department of Psychiatry, General University Hospital throughout the entire study period.

A clinical evaluation of the patients was performed by an experienced psychiatrist. The Structured Clinical Interview MINI 5.0 was used for diagnostic assessment of the patients. None of the studied subjects suffered from diabetes mellitus, thyroid disorder and/or acute infectious disease. None of the studied subjects had malignant tumor. All women included in the study had no allergies. The duration of AN disorder was $9 \pm 1.8$ years. All of the patients were firstly examined before entering specific treatment programs and were drug-free for more than three months prior to first sampling.

During the realimentation period ( $46 \pm 2$ days), all AN patients were prescribed 3 main dishes, two snacks and one second dinner. The realimentation diet contained $50 \%$ carbohydrates, $25 \%$ fats and $25 \%$ proteins; the total daily energy intake was $2300 \mathrm{kcal} /$ day. All meals and snacks were eaten under supervision.

Healthy control women had been free of any medication and had no history of obesity or malnutrition, hypertension, gastrointestinal disease, eating disorder or other psychiatric disorder. Blood tests confirmed normal blood count, liver and renal functions. All healthy women had regular menstrual cycle while all patients with AN had amenorrhea which was not affected by the realimentation. All patients with AN were hospitalized in the Department of Psychiatry, General University Hospital in Prague. All healthy control women were enrolled into study by local advertisement.

Written informed consent was provided by all participants before being enrolled in the study. The study was approved by the Human Ethical Review Committee, First Faculty of Medicine and General University Hospital, Prague, Czech Republic, and was performed in accordance with the guidelines proposed in the Declaration of Helsinki.

\section{Anthropometric examination and blood sampling}

All patients with AN were examined twice; at a basal state before the beginning of any treatment and after two months of partial realimentation while normal-weight 
healthy women were examined only once. All subjects were measured and weighted and BMI was calculated. Body fat content was estimated by bioimpedance analysis (Bodystat 1500, Bodystat Ltd., UK) and by dual energy X-ray absorptiometry (DEXA). Bone mineral density was also estimated by DEXA on QDR 4500A bone densitometer (Hologic, Waltham, MA, USA). Resting energy expenditure was determined by indirect calorimetry (Vmax ENCORE Viasys ${ }^{\mathrm{TH}}$ HEALTHCARE, SensorMedics BV, Netherlands). Blood samples for Pref-1, other hormonal and biochemical parameters measurements were withdrawn between 0700 and $0800 \mathrm{~h}$ after $12 \mathrm{~h}$ of overnight fasting. All of the blood drawings in control group were performed at the beginning of follicular phase of menstrual cycle 3-5 days after the end of menstrual period. Both the AN patients and control subjects were instructed to refrain from food intake after 7 PM on the day preceding the blood drawing. Water was the only drink allowed to all subjects after 7 PM. Serum was separated by centrifugation and stored at $-80{ }^{\circ} \mathrm{C}$ until being assayed.

\section{Hormonal and biochemical assays}

Serum Pref-1 concentrations were measured by a commercial ELISA kit (R\&D Systems, Minneapolis, U.S.A.). The sensitivity was $12 \mathrm{pg} / \mathrm{ml}$, and the intra- and interassay variability was less than 5.0 and $15.0 \%$, respectively.

Serum insulin concentrations were measured by a commercial RIA kit (Cis Bio International, Gif-surYvette, France). Sensitivity was $2.0 \mu \mathrm{IU} / \mathrm{ml}$, and the intra- and interassay variability was 4.2 and $8.8 \%$, respectively.

Serum leptin concentrations were measured by commercial ELISA kit (BioVendor, Brno, Czech Republic). Sensitivity was $0.12 \mathrm{ng} / \mathrm{ml}$ and the intra- and interassay variability was 1.7 and $8.0 \%$, respectively.

Serum levels of TSH and free T4 were measured by chemiluminiscence immunoassay (CLIA) on ADVIA Centauer analyzer (Siemens, Healthcare Diagnostics Inc, Tarrytown, NY, USA). Sensitivity was $0.004 \mathrm{mIU} / 1$ for $\mathrm{TSH}$ and $0.1 \mathrm{ng} / \mathrm{dl}$ for free $\mathrm{T} 4$, and the intra- and interassay variability was less than $5 \%$ for both measurement. Serum biochemical parameters (glucose, total and HDL-cholesterol, triglycerides and albumin) were measured by standard laboratory methods on Modular SWA analyzer (Roche Diagnostics, GmbH, Mannheim, Germany), the value of LDL-cholesterol was calculated by Friedewald formula.

\section{Statistical analysis}

The statistical analysis was performed on SigmaStat software (Jandel Scientific, San Rafael, CA). Results are expressed as mean \pm S.E.M. (the standard error of the mean). Unpaired t-test or Mann-Whitney test were used for comparisons of serum parameters between control group and group of patients with AN as appropriate. Paired t-test or Wilcoxon signed rank test were used for the comparisons of serum Pref-1 levels and of other studied parameters in patients with AN before and after partial realimentation as appropriate. The correlations between the values were estimated by Spearman correlation test. A $\mathrm{p}$ value $<0.05$ denoted statistical significance.

\section{Results}

Anthropometric, hormonal and biochemical characteristics of control group of normal-weight healthy women and patients with anorexia nervosa before and after partial realimentation are shown in Table 1. At baseline, body weight, body mass index (BMI), body fat content, fasting glucose, serum insulin, TSH, free T4, leptin, total serum protein and resting energy expenditure, femoral and lumbar bone mineral density in patients with anorexia nervosa were significantly lower relative to control subjects. Age and serum albumin concentrations did not significantly differ between the groups.

Partial realimentation of patients with anorexia nervosa significantly increased body weight, body mass index, body fat content, fasting glucose, serum insulin, serum leptin, total serum protein, serum albumin and resting energy expenditure.

Serum Pref-1 concentrations are shown in Figure 1. Pre-treatment serum Pref-1 levels in patients with anorexia nervosa did not significantly differ from those in control subjects $(0.26 \pm 0.02$ vs. $0.32 \pm 0.05 \mathrm{ng} / \mathrm{ml}$, $\mathrm{p}=0.295$ ), also post-treatment serum Pref-1 levels in patients with AN did not significantly differ from those in control subjects $(0.35 \pm 0.04$ vs. $0.32 \pm 0.05 \mathrm{ng} / \mathrm{ml}$, $\mathrm{p}=0.578$ ). Partial realimentation significantly increased serum Pref-1 levels ( $p=0.015$ ) (Fig. 3).

Relationships between Pref-1 concentrations and other anthropometric, biochemical and hormonal parameters were calculated using Spearman correlation test in our whole group of study subjects which included both the pre-alimentation patients with $\mathrm{AN}$ and the control subjects. 
Table 1. Anthropometric, hormonal and biochemical characteristics of the control group of normal-weight healthy women and patients with anorexia nervosa before and after partial realimentation.

\begin{tabular}{|c|c|c|c|}
\hline & $\begin{array}{c}\text { Controls } \\
(n=16)\end{array}$ & $\begin{array}{c}\text { AN before } \\
\text { realimentation } \\
\quad(n=18)\end{array}$ & $\begin{array}{c}\text { AN after } \\
\text { realimentation } \\
\quad(n=18)\end{array}$ \\
\hline Age (years) & $22.69 \pm 0.76$ & $24.39 \pm 1.21$ & $24.39 \pm 1.21$ \\
\hline Weight (kg) & $64.23 \pm 1.91$ & $42.59 \pm 0.98^{a}$ & $47.63 \pm 0.91^{a, b}$ \\
\hline Body mass index $\left(\mathrm{kg} / \mathrm{m}^{2}\right)$ & $21.80 \pm 0.51$ & $15.58 \pm 0.28^{a}$ & $17.44 \pm 0.24^{a, b}$ \\
\hline Body fat content (bodystat) (\%) & $20.07 \pm 1.4$ & $10.31 \pm 1.8^{a}$ & $13.3 \pm 1.32^{a, b}$ \\
\hline Body fat content (DEXA)\% & $26.19 \pm 1.52$ & $14.86 \pm 1.58^{a}$ & $18.71 \pm 1.41^{a, b}$ \\
\hline Resting energy expenditure (kcal/day) & $1405.75 \pm 30.63$ & $1055.44 \pm 35.81^{a}$ & $1166.00 \pm 24.02^{a, b}$ \\
\hline Total cholesterol $(\mathrm{mmol} / \mathrm{l})$ & $4.32 \pm 0.19$ & $7.64 \pm 3.10$ & $5.18 \pm 0.24^{a}$ \\
\hline HDL-cholesterol (mmol/l) & $1.76 \pm 0.09$ & $1.57 \pm 0.10$ & $1.63 \pm 0.1$ \\
\hline LDL-cholesterol (mmol/l) & $2.15 \pm 0.13$ & $2.37 \pm 0.17$ & $2.9 \pm 0.20^{a}$ \\
\hline Triacylglycerides (mmol/l) & $0.91 \pm 0.12$ & $1.52 \pm 0.16^{a}$ & $1.46 \pm 0.17^{a}$ \\
\hline Fasting glucose (mmol/l) & $4.38 \pm 0.08$ & $3.97 \pm 0.07^{a}$ & $4.26 \pm 0.08^{b}$ \\
\hline Serum insulin $(\mu U I / m l)$ & $19.29 \pm 1.12$ & $15.79 \pm 0.75^{a}$ & $16.1 \pm 0.95^{a, b}$ \\
\hline TSH $(m I U)$ & $2.25 \pm 0.27$ & $1.45 \pm 0.21^{a}$ & - \\
\hline Free T4 (mIU) & $14.19 \pm 0.50$ & $12.35 \pm 0.51^{a}$ & - \\
\hline Leptin $(n g / m l)$ & $11.8 \pm 1.78$ & $0.97 \pm 0.23^{a}$ & $2.62 \pm 0.66^{a, b}$ \\
\hline Total serum protein $(g / l)$ & $78.4 \pm 1.28$ & $69.66 \pm 1.84^{a}$ & $75.26 \pm 0.97^{b}$ \\
\hline Albumin $(g / l)$ & $46.36 \pm 0.99$ & $44.23 \pm 1.03$ & $47.32 \pm 0.66^{b}$ \\
\hline Total bone mineral density $\left(\mathrm{g} / \mathrm{cm}^{2}\right)$ & $1.08 \pm 0.02$ & $1.05 \pm 0.02$ & $1.04 \pm 0.02^{a}$ \\
\hline$B M D$ femoral $\left(\mathrm{g} / \mathrm{cm}^{2}\right)$ & $0.96 \pm 0.02$ & $0.78 \pm 0.03^{a}$ & - \\
\hline BMD lumbal $\left(\mathrm{g} / \mathrm{cm}^{2}\right)$ & $0.99 \pm 0.03$ & $0.86 \pm 0.03^{a}$ & - \\
\hline
\end{tabular}

Values are means \pm S.E.M. Statistical significance is from unpaired and paired t-test or Mann-Whitney test. ${ }^{a} \mathrm{P}<0.05$ vs. controls. ${ }^{b} \mathrm{P}<0.05$ vs. anorexia nervosa before realimentation.

\section{Serum preadipocyte factor - 1 in anorexia nervosa}

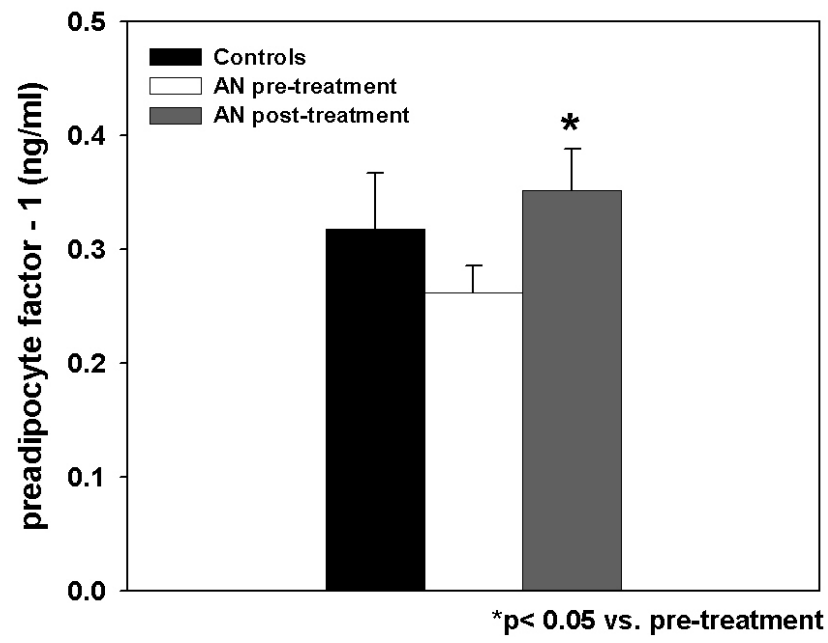

Fig. 1. Serum concentrations of preadipocyte factor-1 in control group (black bar) and patients with anorexia nervosa before (open bar) and after realimentation (gray bar).

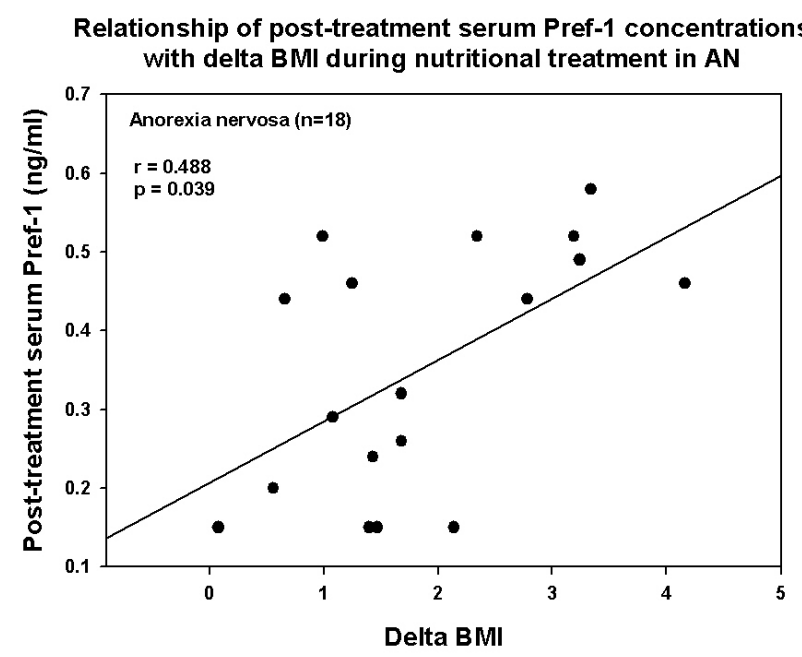

Fig. 2. Relationship of post-treatment preadipocyte factor-1 concentrations and the change of body mass index after realimentation. 


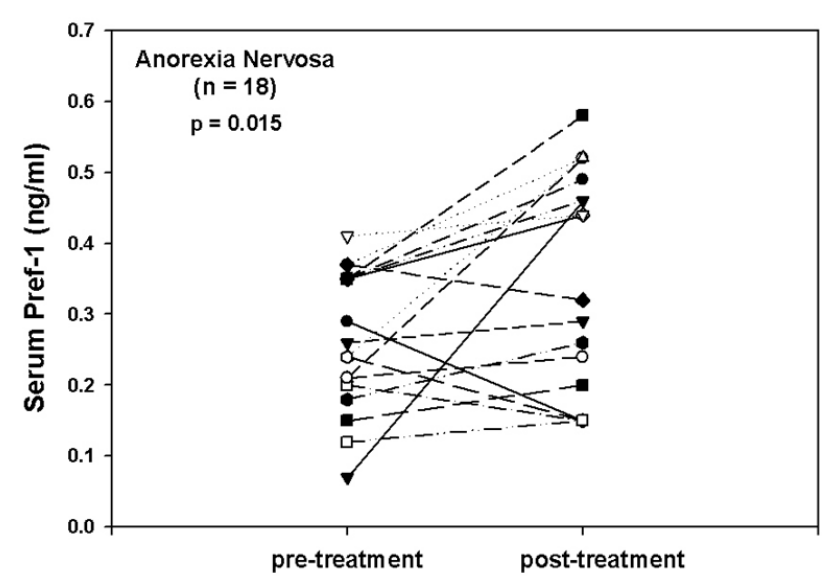

Fig. 3. The influence of partial refeeding on serum concentrations of preadipocyte factor- $1(\mathrm{ng} / \mathrm{ml})$ shown for each patient with anorexia nervosa individually ( $\mathrm{AN} ; \mathrm{n}=18)$.

At baseline, no significant relationships between circulating Pref-1 and other studied parameters were found. The same was true for relationship between changes in Pref-1 levels and changes in BMI after realimentation $(\mathrm{p}=0.161)$. The only significant relationship detected was a positive correlation between post-treatment Pref-1 levels and the change of BMI after realimentation of anorexia nervosa patients (Fig. 2) while no significant.

\section{Discussion}

The most important finding of this study is that partial realimentation of patients with anorexia nervosa significantly increased circulating concentrations of Pref-1. On the contrary, nor the baseline or postreatment Pref-1 levels in anorexia nervosa group significantly differed from those of healthy normal-weight women suggesting that dynamic change in circulating Pref-1 levels might be more important that its absolute concentrations under the circumstances of realimentation.

Pref- 1 is a 385 amino acid protein belonging to the family of epidermal growth factor-like repeat containing proteins (Sul 2009). In humans, it is highly expressed by preadipocytes but not by adipocytes. Other Pref-1 expressing cells include pancreatic islet cells, thymic stromal cells and adrenal gland cells (Sul 2009). Experimental studies have demonstrated that circulating Pref-1 could directly contribute to the regulation of adipose tissue stores and lipid and glucose metabolism (Moon et al. 2002, Lee et al. 2003, Villena et al. 2008). Mice with Pref-1 knockout show growth retardation and skeletal abnormalities as well as increased adiposity when fed a high fat diet (Moon et al. 2002) supporting the role of Pref-1 in the regulation of adipocyte differentiation. On the contrary, young adult mice overexpressing soluble Pref-1 exhibit a marked reduction in white adipose tissue mass as a result of impaired adipocyte differentiation (Lee et al. 2003). These mice are resistant to high fat dietinduced obesity but they develop hypetriglyceridemia, impaired glucose tolerance and insulin resistance mostly due to inability to expand adipose tissue mass (Villena et al. 2008).

Only one human study to date was focused on the changes circulating Pref-1 levels in humans (Fazeli et al. 2010). In this study, Fazeli and colleagues describe significantly higher circulating Pref-1 levels in untreated patients with anorexia nervosa compared to healthy normal weight women. Furthermore, Pref-1 concentrations in this study positively correlated with marrow fat of the proximal femoral metaphysis. In contrast to Fazeli's results, we did not find significant differences in circulating Pref-1 levels between anorexia nervosa patients and healthy normal-weight women. The reason for the differences in Pref- 1 concentrations in Fazeli's and ours study is unclear. It may be caused by the fact that our group of anorexia nervosa patients was leaner compared to patients in Fazeli's study and possibly also by different disease duration or other unknown factors.

Importantly, partial realimentation in our study significantly increased circulating Pref-l levels suggesting that the change in nutritional status can significantly influence Pref-1 production and/or its release from adipose tissue. This finding is interesting given the fact that we were not able to detect any significant relationship of circulating Pref-1 levels with anthropometric or biochemical nutritional parameters in our group of study subjects. Overall, these findings suggest that dynamic changes of nutritional state but not its chronic status influence Pref-1 concentrations. Nevertheless, it should be mentioned that our study only tested dynamic changes of Pref-1 in anorexia nervosa group after realimentation while no overalimentation was performed in control group. Therefore the changes observed in anorexia nervosa group cannot be generally extrapolated to other realimentation or overalimentation states such as obesity.

The role of circulating Pref-1 mostly remains to be elucidated (Lee et al. 2003). Both in vitro and in vivo experimental studies have shown that Pref-1 is a strong inhibitor of adipocyte differentiation suggesting its major 
paracrine role in adipose tissue (Smas and Sul 1993). Increased Pref-1 levels in Pref-1 overexpressing transgenic mice were also associated with increased triglyceride concentrations, impaired glucose tolerance and decreased insulin sensitivity (Villena et al. 2008). Experimental data suggest that metabolic abnormalities in Pref-1 overexpressing mice were probably secondary due to partial lipodystrophy caused by impaired adipocyte differentiation rather than due to direct negative metabolic effects of Pref-1 in other tissues or organs (Lee et al. 2003).

In addition to increased Pref- 1 levels in patients with anorexia nervosa after partial realimentation we also found that post-realimentation Pref-1 levels significantly correlated with change of BMI after partial realimentation. This relationship may suggest that the production of Pref-1 by adipose tissue after realimentation reflects its differentiation capacity and/or number of preadipocytes. The patients with higher Pref-1 levels and higher preadipocytes number in adipose tissue thus could gain more weight compared to patients with lower number of preadipocytes and Pref-1 levels. However, at this point this hypothesis remains only speculative and has to be directly tested in other studies.

In conclusion, we have demonstrated that circulating levels of Pref-1 in untreated patients with anorexia nervosa do not differ from those of healthy normal-weight women but they are significantly increased by partial realimentation. The relationship between post-realimentation Pref-1 levels and increase in body mass index of anorexia nervosa patients suggest that Pref-1 concentration after realimentation may reflect the differentiation capacity of adipose tissue in anorexia nervosa patients.

\section{Conflict of Interest}

There is no conflict of interest.

\section{Acknowledgements}

Supported by MSM0021620814, MZOVFN2005 and SVV-2010-260503.

\section{References}

BARANOWSKA B, WASILEWSKA-DZIUBINSKA E, RADZIKOWSKA M, PLONOWSKI A, ROGUSKI K: Neuropeptide Y, galanin, and leptin release in obese women and in women with anorexia nervosa. Metabolism 46: 1384-1389, 1997.

BERESFORD JN, BENNETT JH, DEVLIN C, LEBOY PS, OWEN ME: Evidence for an inverse relationship between the differentiation of adipocytic and osteogenic cells in rat marrow stromal cell cultures. J Cell Sci 102: 341$351,1992$.

DOLEZALOVA R, LACINOVA Z, DOLINKOVA M, KLEIBLOVA P, HALUZIKOVA D, HOUSA D, PAPEZOVA H, HALUZIK M: Changes of endocrine function of adipose tissue in anorexia nervosa: comparison of circulating levels versus subcutaneous mRNA expression. Clin Endocrinol (Oxf) 67: 674-678, 2007.

DOSTALOVA I, HALUZIK M: The role of ghrelin in the regulation of food intake in patients with obesity and anorexia nervosa. Physiol Res 58: 159-170, 2009.

DOSTAlOVA I, SEDLACKOVA D, PAPEZOVA H, NEDVIDKOVA J, HALUZIK M: Serum visfatin levels in patients with anorexia nervosa and bulimia nervosa. Physiol Res 58: 903-907, 2009.

FAZELI PK, BREDELLA MA, MISRA M, MEENAGHAN E, ROSEN CJ, CLEMMONS DR, BREGGIA A, MILLER KK, KLIBANSKI A: Preadipocyte factor-1 is associated with marrow adiposity and bone mineral density in women with anorexia nervosa. J Clin Endocrinol Metab 95: 407-413, 2010.

FOPPIANI L, LUISE L, RASORE E, MENICHINI U, GIUSTI M: Frequency of recovery from anorexia nervosa of a cohort patients re-evaluated on a long-term basis following intensive care. Eat Weight Disord 3: 90-94, 1998.

FRISCH RE, MCARTHUR JW: Menstrual cycles: fatness as a determinant of minimum weight for height necessary for their maintenance or onset. Science 185: 949-951, 1974.

GRINSPOON S, GULICK T, ASKARI H, LANDT M, LEE K, ANDERSON E, MA Z, VIGNATI L, BOWSHER R, HERZOG D, KLIBANSKI A: Serum leptin levels in women with anorexia nervosa. J Clin Endocrinol Metab 81: 3861-3863, 1996. 
HALUZIKOVA D, DOSTALOVA I, KAVALKOVA P, ROUBICEK T, MRAZ M, PAPEZOVA H, HALUZIK M: Serum concentrations of adipocyte fatty acid binding protein in patients with anorexia nervosa. Physiol Res $\mathbf{5 8}$ : 577-581, 2009.

HOEK HW, VAN HOEKEN D: Review of the prevalence and incidence of eating disorders. Int J Eat Disord 34: $383-$ 396, 2003.

HOUSOVA J, ANDERLOVA K, KRIZOVA J, HALUZIKOVA D, KREMEN J, KUMSTYROVA T, PAPEZOVA H, HALUZIK M: Serum adiponectin and resistin concentrations in patients with restrictive and binge/purge form of anorexia nervosa and bulimia nervosa. J Clin Endocrinol Metab 90: 1366-1370, 2005.

LEE K, VILLENA JA, MOON YS, KIM KH, LEE S, KANG C, SUL HS: Inhibition of adipogenesis and development of glucose intolerance by soluble preadipocyte factor-1 (Pref-1). J Clin Invest 111: 453-461, 2003.

MOON YS, SMAS CM, LEE K, VILLENA JA, KIM KH, YUN EJ, SUL HS: Mice lacking paternally expressed Pref1/Dlk1 display growth retardation and accelerated adiposity. Mol Cell Biol 22: 5585-5592, 2002.

SIGMAN GS: Eating disorders in children and adolescents. Pediatr Clin North Am 50: 1139-1177, vii, 2003.

SMAS CM, SUL HS: Pref-1, a protein containing EGF-like repeats, inhibits adipocyte differentiation. Cell 73: 725-734, 1993.

STOVING RK, HANGAARD J, HANSEN-NORD M, HAGEN C: A review of endocrine changes in anorexia nervosa. J Psychiatr Res 33: 139-152, 1999.

SUL HS: Minireview: Pref-1: role in adipogenesis and mesenchymal cell fate. Mol Endocrinol 23: 1717-1725, 2009.

TAGAMI T, SATOH N, USUI T, YAMADA K, SHIMATSU A, KUZUYA H: Adiponectin in anorexia nervosa and bulimia nervosa. J Clin Endocrinol Metab 89: 1833-1837, 2004.

TANAKA M, NARUO T, YASUHARA D, TATEBE Y, NAGAI N, SHIIYA T, NAKAZATO M, MATSUKURA S, NOZOE S: Fasting plasma ghrelin levels in subtypes of anorexia nervosa. Psychoneuroendocrinology 28: 829835, 2003.

VERMA S, RAJARATNAM JH, DENTON J, HOYLAND JA, BYERS RJ: Adipocytic proportion of bone marrow is inversely related to bone formation in osteoporosis. J Clin Pathol 55: 693-698, 2002.

VILLENA JA, CHOI CS, WANG Y, KIM S, HWANG YJ, KIM YB, CLINE G, SHULMAN GI, SUL HS: Resistance to high-fat diet-induced obesity but exacerbated insulin resistance in mice overexpressing Pref-1: a new model of partial lipodystrophy. Diabetes 57: 3258-3266, 2008.

WANG Y, KIM KA, KIM JH, SUL HS: Pref-1, a preadipocyte secreted factor that inhibits adipogenesis. $J$ Nutr 136: 2953-2956, 2006. 